\title{
MOVIMENTAÇÃO DE PARTÍCULAS DE CALCÁRIO NO PERFIL DE UM CAMBISSOLO EM PLANTIO DIRETO(1)
}

\author{
A. S. AMARAL (2), I. ANGHINONI(3), R. HINRICHS ${ }^{(4)}$ \& I. BERTOL (5)
}

\begin{abstract}
RESUMO
A aplicação superficial de calcário tem-se mostrado eficiente na correção da acidez do solo no sistema plantio direto. Ao contrário do esperado, os efeitos da aplicação de calcário têm ocorrido em profundidade e em períodos de tempo relativamente curtos, apesar da sua baixa solubilidade no solo. Os objetivos deste trabal ho foram: (a) detectar a presença dos minerais calcita e dolomita do calcário no solo; (b) verificar as alterações químicas relacionadas com a acidez no perfil do solo, decorrentes da aplicação de calcário na superfície, e (c) verificar a movimentação de partículas de calcário e a sua participação na correção da acidez do solo no sistema plantio direto. Foi realizado um experimento em casa de vegetação, utilizando colunas de PVC com amostras indeformadas de um Cambissolo Húmico alumínico léptico argiloso, manejado há cinco anos em sistema plantio direto. A dose de calcário comercial (PR NT $76 \%$ ) aplicada no topo da coluna correspondeu a $12 \mathrm{Mg} \mathrm{ha}^{-1}$. Aos sete dias da aplicação do calcário, já foi possível verificar o transporte de partículas finas $(<0,105 \mathrm{~mm})$ do calcário aplicado na superfície do solo até à profundidade de $20 \mathrm{~cm}$, visto que foram detectados os minerais calcita e dolomita nesta profundidade. Os efeitos nos atributos quími cos do solo, decorrentes da aplicação de calcário na superfície, ocorreram em todo o perfil, sendo mais expressivos até $10 \mathrm{~cm}$ e aos $20 \mathrm{~cm}$ de profundidade, onde houve acúmulo de calcário. 0 transporte de calcário através da água da chuva pode ser um mecanismo importante na correção da acidez do solo em profundidade no sistema plantio direto.
\end{abstract}

Termos de indexação: calagem superficial, sistema plantio direto, colunas indeformadas de solo.

\footnotetext{
(1) Parte da Tese de Doutorado do primeiro autor, apresentada ao Programa de Pós-Graduação em Ciência do Solo, Universidade Federal do Rio Grande do Sul - UFRGS, e executada com recursos do CNPq, FAPERGS E PRONEX. Trabalho recebido para publicação em dezembro de 2002 e aprovado em janeiro de 2004.

(2) Professor de Solos do Curso de Engenharia Agrícola, Universidade Regional Integrada do Alto Uruguai e das Missões - URI . Campus de Erechim, Caixa Postal 743, CEP 99700-000 Erechim (RS). E-mail: asamaral@uri.com.br

(3) Professor do Departamento de Solos, Universidade Federal do Rio Grande do Sul - UFRGS. CEP 90540-000 Porto Alegre (RS). Bolsista do CNPq. E-mail: ibanghi@ufrgs.br

(4) Professora do Instituto de Geociências, UFRGS. E-mail: ruth@cme.ufrgs.br

(5) Professor da Faculdade de Agronomia, Centro de Ciências Agroveterinárias, Universidade do Estado de Santa Catarina - CAV/ UDESC. Av. Luiz de Camões 2090, Caixa Postal 281, CEP 88520-000 Lages (SC). Bolsista do CNPq. E-mail: a2ib@cav.udesc.br
} 


\title{
SUMMARY: MOVEMENT OF LIME PARTICLES IN THE PROFILE OF AN INCEPTISOL UNDER NO-TILLAGE
}

\begin{abstract}
Surface lime application has shown to be efficient for correcting soil acidity in notillage systems. Contrary to the expected, this effect has occurred in deeper soil layers and in a relatively short time, in spite of thel ow sol ubility of liming materials. Theobjectives of this research were: (a) to detect the presence of cal cite and dolomite minerals originated from lime in the soil; (b) to verify chemical alterations related to soil acidity in the soil profile dueto surfacelime application, and (c) to verify the movement of li me particles and its effects in correcting the soil aci dity in no-tillage system. A greenhouse experiment was conducted with undisturbed columns of an Inceptisol (Haplumbrept), which has been under no-tillage for five years. A commercial lime rate of $12 \mathrm{Mg} \mathrm{ha}^{-1}$ was applied on top of the columns. Seven days after the application of lime it was possibleto verify a transfer of fine limeparticles $(<0.105 \mathrm{~mm})$ from thesoil surface down to $20 \mathrm{~cm}$ soil depth as substantiated by the presence of cal cite and dol omite minerals at this depth. The effects of surface lime application on chemical soil attributes were observed throughout the soil profile, but were more evident up to $10 \mathrm{~cm}$ and also at a depth of $20 \mathrm{~cm}$, where there was accumulation of lime. The movement of lime particles with rain water may be an important mechanism of correction of soil subsurface soil acidity in no-tillage systems.
\end{abstract}

Index terms: surfacelime, no-tillage system, undeformed soil columns.

\section{INTRODUÇÃO}

O plantio direto constitui uma excelente alternativa de manejo do solo, pois, além de reduzir eficazmente a erosão, preserva a qualidade estrutural do solo obtida ao longo do tempo. O uso desse sistema de manejo, embora ocasione um aumento da densidade do solo na superfície, com conseqüente diminuição do volume de macroporos nessa camada e da rugosidade superficial (Bertol et al., 2000), não tem prejudicado a infiltração de água (Schick et al., 2000; Petrere \& Anghinoni, 2001), causado erosão hídrica (Schick et al ., 2000) ou afetado o desenvolvimento de raízes das plantas (Sá \& Petrere, 1995), desde que se observem os fundamentos do sistema plantio direto.

Com o decorrer do tempo, em geral, no solo sob plantio direto, verifica-se um aumento de bioporos pela ação contínua de raízes eal ta atividade da meso e macrofauna (Gassen \& Kocchann, 1998; Wuest, 2001). Os bioporos e a estrutura de boa qualidade do solo, graças ao seu não-revolvimento, permitem a formação de canais, os quais são mantidos intactos e contínuos no perfil do solo (Gassen \& Kocchann, 1998). A não-mobilização do solo e o aumento da matéria orgânica determinam, ao longo do tempo, um ambiente propício para a atividade de minhocas, larvas de insetos e de outros organismos e o aumento da atividade microbiana. Esses processos contribuem para a formação e estabilização dos agregados do solo, melhorando também a sua estrutura (Molope et al., 1987). Quando essas propriedades físicas são preservadas, as taxas de infiltração instantânea de água no sistema plantio direto e em pastagem nativa são maiores do que no preparo de solo com revolvimento convencional (Schick et al., 2000; Petrere \& Anghinoni, 2001).

Os atributos físi cos do solo inerentes ao sistema plantio direto, associados às condições de clima e solo no Sul do País, podem possibilitar a movimentação, no perfil do solo, de partículas finas de calcário que não reagiram na superfície. A migração das partículas pode ser importante para explicar, pelo menos em parte, os efeitos na neutral ização da acidez e na concentração de cálcio e magnésio verificados na subsuperfície do sol o após períodos relativamente curtos da aplicação superficial de calcário.

Uma das formas de comprovar efetivamente a movimentação de partículas finas do cal cário no perfil do solo é a identificação de calcita e dol omita no solo. O problema é que, geralmente, as quantidades de partículas de cal cário transportadas são muito pequenas em relação ao volume de solo. A principal técnica de identificação de minerais, a difratometria de raios-X (DRX), é de aplicabilidade limitada quando eles estão presentes em concentrações menores do que $5 \%$ nas amostras de solo (Trollard et al., 1995). Esse problema pode ser contornado pelo uso de métodos complementares à técnica de DRX, como a análise térmica diferencial (ATD) e a microscopia el etrônica.

As características peculiares do sistema plantio diretotambém admitem a dissol uçãoe reprecipitação de carbonatos no solo ao longo do tempo. A dissolução dos minerais constituintes do calcário (cal cita edolomita) na superfície do sol o pode saturar

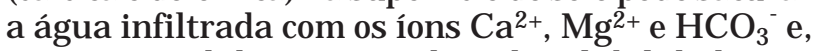
assim, à medida que o produto de solubilidade seja excedido e outras condições necessárias estejam 
presentes (baixa pressão parcial de $\mathrm{CO}_{2} \mathrm{e}$ evaporação), os referidos íons podem reprecipitar em camadas inferiores. Admitindo-se tal possibilidade e detectada a dolomita e calcita por meio da DRX, uma questão relevante seria como distinguir se os minerais identificados no interior do solo seriam litogênicos (partículas originais do cal cário aplicado na superfície do solo que foram transportadas sem sedissolverem) ou pedogênicos (sofreram os processos de dissol ução e repreci pitação).

Os objetivos deste trabal ho foram: (a) detectar a presença dos minerais cal cita e dol omita do cal cário no solo; (b) verificar as alterações químicas relacionadas com a acidez no perfil do solo, decorrentes da aplicação de cal cário na superfície, e (c) verificar a movimentação de partículas de cal cário e a sua partici pação na correção da acidez do sol o no sistema plantio direto.

\section{MATERIAL E MÉTODOS}

O experimento foi realizado em colunas de PVC que continham amostras indeformadas de solo em casa de vegetação, no Departamento de Solos da Faculdade de Agronomia da Universidade Federal do Rio Grande do Sul (UFRGS), entre outubro de 2000 e abril de 2001.

Utilizaram-se amostras de um Cambissolo Húmico alumínico léptico argil oso, col etadas em um experimento na Universidade do Estado de Santa Catarina (UDESC) - Campus do Centro de Ciências Agroveterinárias de Lages (SC). O experimento foi iniciado em maio de 1995, com a aplicação de cal cário, fósforo e potássio, incorporados ao sol o com uma aração e duas gradagens, deacordo com CFSRS/ SC (1994). F oram utilizados, na ocasião, 3,9 Mg ha-1 decal cário dol omítico (PRNT $100 \%), 125$ kg ha-1 de superfosfato triplo e $100 \mathrm{~kg} \mathrm{ha}^{-1}$ de cloreto de potássio, iniciando-se, em seguida, o plantio das culturas, sendo sempre mil ho (Zea mays) no verão e ervilhaca comum (Vicia sativa) no inverno. O experimento foi manejado no sistema plantio direto, sem reaplicação de calcário até o momento da amostragem (25/10/2000).

Na ocasião da amostragem do sol o, o experimento estava sendo cultivado com ervilhaca comum. Para facilitar a retirada das colunas do solo, as plantas foram eliminadas nos locais de coleta. Coletaramse amostras indeformadas em colunas de PVC de $12,0 \mathrm{~cm}$ de diâmetro por $22 \mathrm{~cm}$ dealtura. A camada de coleta no solo foi de $0-20 \mathrm{~cm}$. As características químicas do solo nessa camada eram: $\mathrm{pH}\left(\mathrm{H}_{2} \mathrm{O}\right) 4,7$; fósforo disponível (Mehlich-1) 6,0 $\mathrm{mg} \mathrm{dm}^{-3}$; potássio disponível (Mehlich-1) $74 \mathrm{mg} \mathrm{dm}^{-3}$; matéria orgânica (combustãoúmida) $42 \mathrm{~g} \mathrm{~kg}^{-1} ; \mathrm{H}+\mathrm{Al} 8,8 \mathrm{cmol}_{\mathrm{C}} \mathrm{dm}^{-3}$; alumínio trocável ( $\left.\mathrm{KCl} 1 \mathrm{~mol} \mathrm{~L}^{-1}\right) 2,5 \mathrm{cmol}_{\mathrm{c}} \mathrm{dm}^{-3}$, cálcio trocável ( $\left.\mathrm{KCl} 1 \mathrm{~mol} \mathrm{~L}^{-1}\right) 5,5 \mathrm{cmol}_{\mathrm{c}} \mathrm{dm}^{-3} \mathrm{e}$ magnésio trocável $\left(\mathrm{KCl} 1 \mathrm{~mol} \mathrm{~L}^{-1}\right) 4,0 \mathrm{cmol}_{\mathrm{C}} \mathrm{dm}^{-3}$, determinados conforme Tedesco et al. (1995). A necessidade de calcário nessa amostragem (25/10/ 2000) foi de 9,9 $\mathrm{Mg} \mathrm{ha}^{-1}$ para el evar o $\mathrm{pH}$ em água a 6,0 (PRNT $100 \%$ ). A composição granulométrica do solo correspondeu a $430 \mathrm{~g} \mathrm{~kg}^{-1}$ de argila, $100 \mathrm{~g} \mathrm{~kg}^{-1}$ de areia e $470 \mathrm{~g} \mathrm{~kg}^{-1}$ de silte.

Após a coleta, as colunas foram transferidas para câmara de crescimento, com condições de temperatura eluminosi dade control adas e semeada a aveia preta. Após o desbaste, deixaram-se três plantas por coluna. A coleta da parte aérea foi realizada 70 dias após a semeadura.

Após a coleta da parte aérea das plantas, adicionou-se parafina derretida nas bordas internas das colunas, a partir da superfície do solo, com o objetivo deimpedir ofluxo preferencial deágua junto às paredes das colunas. $\mathrm{Na}$ extremidade inferior das colunas, prendeu-se um filtro de papel Whatman $n^{\circ} 42$, que era trocado semanalmente. Adaptou-se também um funil de plástico na base de cada coluna. O conjunto (coluna, filtro e funil) foi colocado sobre um becker de vidro $(500 \mathrm{~mL}$ ) para receber o material percolado. Retiraram-setodos os resíduos orgânicos (matéria orgânica leve) da superfície das colunas e aplicaram-se $400 \mathrm{~mL}$ de água destilada em cada coluna, antes da aplicação dos tratamentos, com o objetivo de eliminar possíveis interferências de ácidos orgânicos remanescentes.

Após a umi dade do sol o se estabilizar em $\pm 18 \%$, foram aplicados os tratamentos com calcário dolomítico comercial (PRNT 76 \%; PN 82,64\%; CaO $24 \%$ e MgO $16 \%$ ).

Os tratamentos consistiram da aplicação, ou não, na superfície do solo, de 14,3 g por col una de cal cário dolomítico, equivalente a uma dose de $12 \mathrm{Mg} \mathrm{ha}^{-1}$. Utilizaram-se somente as partículas de cal cário que passaram pela peneira de 0,105 $\mathrm{mm}$ e que ficaram retidas na de $0,053 \mathrm{~mm}$.

Com base nos dados médios de precipitação pluviométrica da região da área experimental, foram aplicados $400 \mathrm{~mL}$ deágua por coluna semanalmente, simulando uma chuva de $35 \mathrm{~mm}$, durante quatro semanas. Após 24 h da aplicação deágua, col etavase a solução percolada e substituía-se o filtro.

Na solução percolada semanalmente, foram determinados os valores de $\mathrm{pH}$ (potenciômetro com eletrodo de vidro combinado), condutividade el étrica (condutivímetrodemesa), Ca eMg (espectrofotometria de absor ção atômica) e $\mathrm{HCO}_{3}^{-}$(titulação com $\mathrm{H}_{2} \mathrm{SO}_{4}$ $0,025 \mathrm{~mol} \mathrm{~L}^{-1}$ ) (Tedesco et al., 1995).

Nas amostras de solo e no material acumulado sobre os filtros, foram realizadas análises mineralógicas, por meio da técnica de DRX, para detectar a presença dos minerais cal cita e dolomita. Utilizou-se equipamento Siemens Diffrac D5000, com goniômetro $\theta-\theta$ (theta-theta), radiação $\mathrm{Cu}-\mathrm{K} \alpha$ emonocromador degrafite. As condições de operação do tubo de raios-X foram de $40 \mathrm{kV}$ e $30 \mathrm{~mA}$. As 
amostras foram passadas em forma de pó natural a 0,60 por minuto. Amostras do calcário dolomítico aplicado na superfície e amostras do calcário acumulado sobre os filtros foram examinadas em microscópio eletrônico de varredura (MEV) J EOL, model oJ SM 5800 (20 kV) do Centro de Microscopia Eletrônica (CME) da UFRGS. Após a retirada do último filtro, as colunas foram congeladas para facilitar a separação, através de secções transversais, em nove camadas: 0-2,0; 2,0-4,0; 4,0-6,0; 6,0-8,0; 8,010,$0 ; 10,-12,0 ; 12,0-14,0 ; 14,0-16,0$ e $16,0-20,0 \mathrm{~cm}$, as quais foram secas e moídas. No solo, foram determinados os valores de $\mathrm{pH}$ em $\mathrm{H}_{2} \mathrm{O}$ e $\mathrm{pH}$ em $\mathrm{CaCl}_{2}$ 0,01 mol L-1 (potenciômetro com el etrodo de vidro combinado), cálcio, magnésio e alumínio trocáveis ( $\mathrm{KCl} 1 \mathrm{~mol} \mathrm{~L}^{-1}$ ) e potássio disponível (Mehlich-1) (Tedesco et al., 1995; E MBRAPA, 1997).

O delineamento experimental utilizado foi de blocos ao acaso com três repetições. Procedeu-se à análise da variância, com a aplicação do teste de médias de Tukey $(P<0,05)$ para diferenciação entre os atributos quími cos avaliados. O model o estatístico utilizado para a análise da variância foi :

$$
\begin{gathered}
\text { Yijk }=\mu+B i+T j+\operatorname{erroa}(i, j)+C k+ \\
\quad \text { errob }(i, k)+T C j, k+\operatorname{erroc}(i, j, k)
\end{gathered}
$$

em que $B=$ blocos $(i=1,2,3) ; T=$ tratamentos $(j=$ $1,2) ; C=$ camadas de solo $(k=1,2, \ldots, 9)$. Para os dados analisados na solução percolada, substituiuse o fator camadas de solo pelo fator tempo ( $\mathrm{k}=$ $7,14,21,28$ dias).

\section{RESULTADOS E DISCUSSÃO}

\section{Movimentação vertical de calcário}

Os minerais calcita e dolomita, principais constituintes do cal cário dol omítico utilizado, foram facilmente identificados em amostras antes da aplicação ao solo (Figura 1a). A identificação desses minerais no solo somente foi possível nas camadas e nos filtros onde o calcário podia ser observado visualmente e não misturado com o solo. I sto aconteceu na primeira camada $(0-2 \mathrm{~cm})$ e onde havia cal cário remanescente, como na última camada (16$20 \mathrm{~cm}$ ), em contato di reto com os filtros, evidenciando que, de fato, as partículas simplesmente percol aram com a água. O calcário acumulado sobre os filtros estava praticamente isento de solo, o que facilitou sua separação e detecção.

As análises por DRX do cal cário encontrado na primeira camada $(0-2 \mathrm{~cm})$ e do cal cário col etado nos filtros após qualquer uma das chuvas mostram a mesma posição e intensidade dos picos e a mesma proporção de altura de picos (Figura $1 b$ ). Nas camadas onde não havia impedimento para infiltração da água, não houve acúmulo de cal cário.
No entanto, quando as col unas foram desmontadas, foi possível verificar visualmente acúmulo de calcário na superfície de agregados na última camada (16-20 cm) do sol o (Figura 2). Todavia, após a moagem do solo existente nas colunas e da conseqüente mistura do calcário com o solo, a identificação de cal cita e dol omita pela DRX não foi possível, provavel mente, em razão das quantidades insuficientes desses minerais no solo analisado (Trollard et al., 1995).

O desl ocamento vertical de partículas do cal cário ocorreu pelo movimento descendente da água aplicada que se infiltrou, por meio de canais e espaços existentes no solo que foram mantidos intactos. Convém ressaltar que, antes da adição dos tratamentos, procurou-se simular uma condição de estiagem (equivalente a 15 dias sem chuva). Além disso, utilizaram-se apenas as partículas mais finas do calcário $(0,105-0,053 \mathrm{~mm})$, que representavam 31 \% da massa do cal cário comercial utilizado, o que explica a ocorrência, na primeira adição deágua, da maior recuperação de cal cário (Quadro 1). A quantidadetotal recuperada decal cário, no final das quatro semanas, chegou a $10,86 \%$ da quantidade total aplicada na superfície do sol o nas colunas.

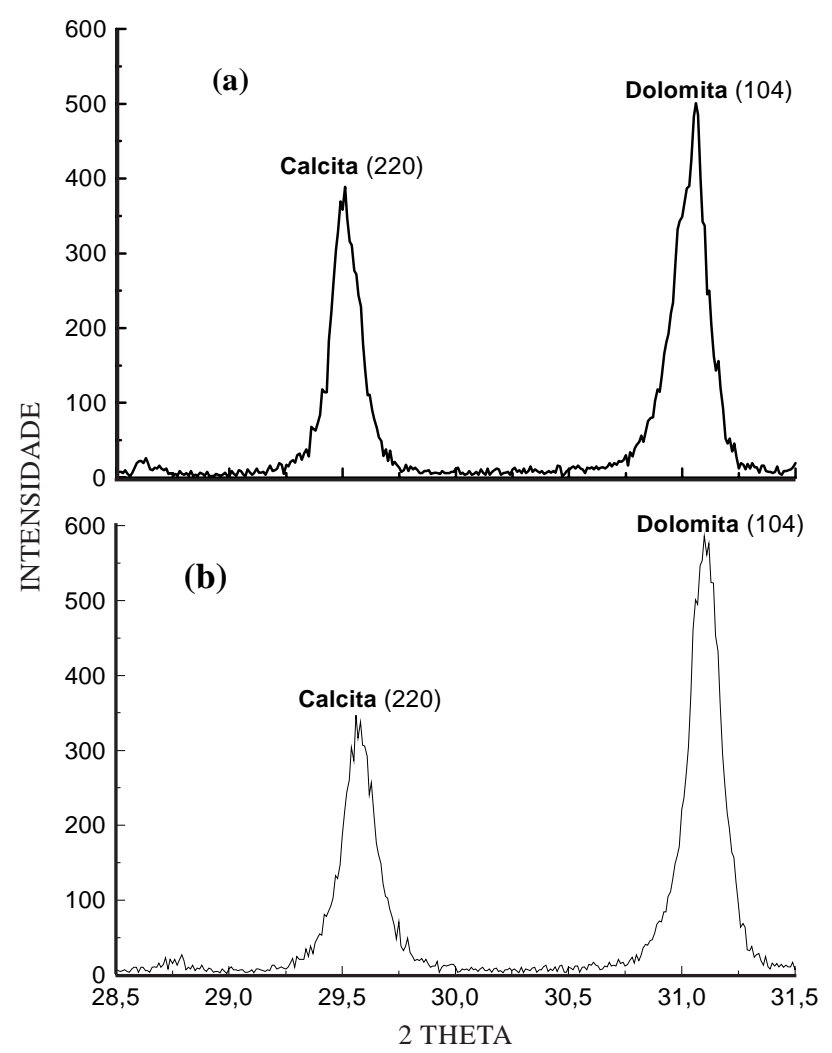

Figura 1. Difratograma de raios-X do calcário dolomítico (a) e das partículas retidas no filtro no fundo da coluna após as primeira adição de água (b). Reflexos nos planos hkl 220 (d = $0,303 \mathrm{~nm})$ de calcita e $104(\mathrm{~d}=0,299) \mathrm{de}$ dolomita. 


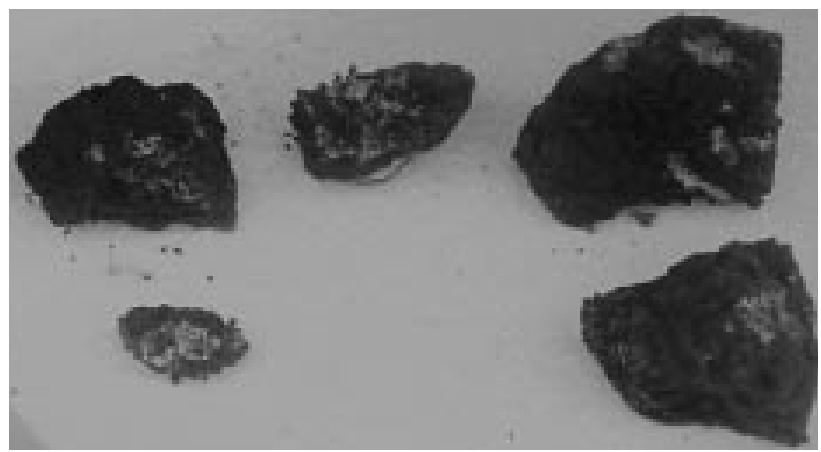

Figura 2. Partículas acumuladas de calcário na superfície de agregados do solo encontrados na última camada $(16-20 \mathrm{~cm})$ da coluna.

Quadro 1. Quantidade de calcário, recuperada semanalmente, $24 \mathrm{~h}$ após cada aplicação de $400 \mathrm{~mL}$ (35 mm de lâmina) de água por coluna

\begin{tabular}{|c|c|c|c|}
\hline \multirow{2}{*}{$\begin{array}{l}\text { Período após a } \\
\text { aplicação do calcário }\end{array}$} & \multicolumn{3}{|c|}{$\begin{array}{c}\text { Quantidade recuperada } \\
\text { de calcário }\end{array}$} \\
\hline & $\begin{array}{c}\text { Água } \\
\text { percolada(1) }\end{array}$ & Filtro(2) & Total \\
\hline dia & 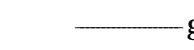 & por coluna & - \\
\hline $\begin{array}{r}7 \\
14 \\
21 \\
28\end{array}$ & $\begin{array}{l}1,03 \\
0,10 \\
0,07 \\
0,05\end{array}$ & $\begin{array}{l}2,80 \\
0,29 \\
0,17 \\
0,15\end{array}$ & $\begin{array}{l}3,83 \\
0,39 \\
0,24 \\
0,20\end{array}$ \\
\hline Total(1) & 1,25 & 3,41 & 4,66 \\
\hline Fração (\%)(2) & 2,93 & 7,93 & 10,86 \\
\hline
\end{tabular}

(1) Soma das quantidades determinadas em cada uma das três repetições. ${ }^{(2)}$ Em relação à quantidade total aplicada nas três colunas $(42,9 \mathrm{~g})$.

A semelhança dos difratogramas do calcário original (Figura 1a) e do cal cário acumulado sobre os filtros (Figura 1b) indica que o cal cário coletado na profundidade da parte inferior da coluna foi transportado da superfície para o interior do solo. No entanto, a distinção entre cal citas ou dol omitas de origem litogênica ou pedogênica em sol os requer análises mais detalhadas de morfologia e de micromorfologia.

Por meio das imagens obtidas em microscópio el etrônico de varredura, pode-se observar que a clivagem romboédrica típica da cal cita e da dol omita (Doner \& Linn, 1989) ocorre tanto nas amostras do cal cário antes da aplicação no sol o (Figura 3a), como no calcário acumulado nos filtros na primeira (Figura 3b) e na segunda coleta (Figura 3c). A clivagem romboédrica, no entanto, apenas dá indíci os de que se trata de calcita ou dolomita, porém não possibilita distinguir entre minerais litogênicos e pedogênicos.
A imagem do calcário coletado após a primeira chuva simulada (Figura 3b) revela a predominância de partículas com granulometria mais fina $(<15 \mu \mathrm{m})$ do que o cal cário original (15 a 100 um - Figura 3a), indicando que as partículas maiores ficaram retidas na rede do solo no interior da coluna. O calcário acumulado no filtro, $24 \mathrm{~h}$ após a segunda chuva simulada (Figura 3c), apresentou maior predomínio de partículas mais finas, aparentando uma textura diferente do calcário aplicado na superfície (Figura 3a). Essas diferenças de granulometria podem ser atribuídas à recristal ização de carbonatos da solução.

Segundo Doner \& Lynn, (1989), a dissolução e a repreci pitação de uma mistura de cal cário cal cítico e dolomítico favorecem a precipitação do calcário calcítico, de modo que, no difratograma, a relação de alturas dos picos da calcita e da dolomita deveria estar alterada. Como isto não se observou (Figura lab), pode-se concluir ser o calcário litogênico. Em condições de campo, no entanto, considerando as interferências dos fatores de solo
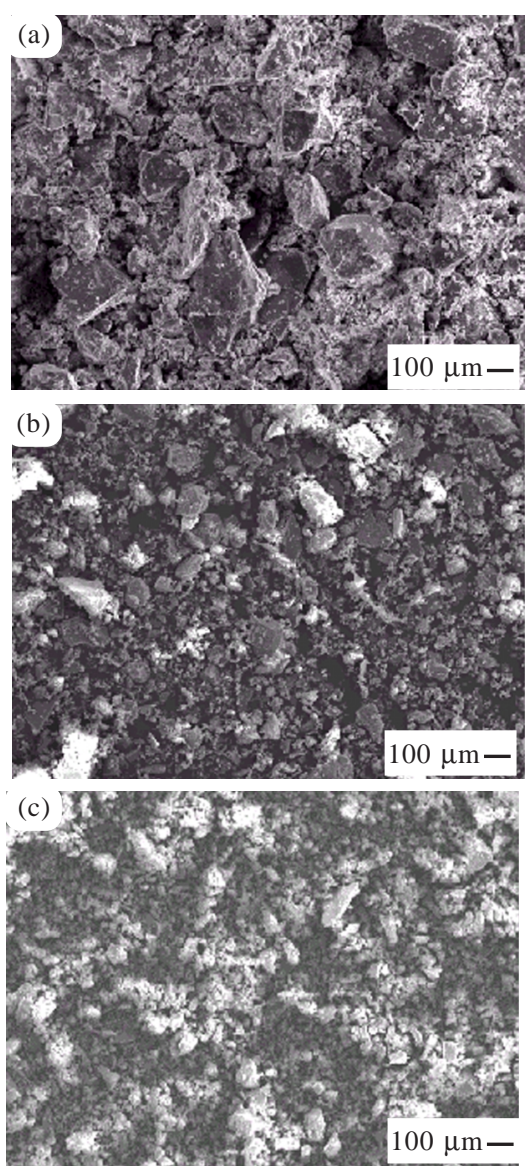

Figura 3. Imagens das partículas do calcário dolomítico obtidas por microscópio eletrônico de varredura (MEV), antes da aplicação na superfície do solo (a), acumulado nos filtros após a primeira (b) e segunda adição de água (c). 
(textura, matéria orgânica, força iônica, pH) e de ambiente (temperatura, umidade e $\mathrm{CO}_{2}$ ), a reprecipitação pode ser favorecida podendo ocorrer a formação de carbonatos pedogêni cos (Levy, 1981).

Vários estudos (Arnauld, 1979; Levy, 1981; Mermut \& Arnauld, 1981) em solos originados de rochas cal cárias mostramas diferenças decalcitas ou dolomitas originadas diretamente do material de origem (litogênicas) daquelas originadas de processos de dissoluçãoe preci pitação dos carbonatos (pedogênicas). Cristais de calcita ou dol omita do tamanho de areia (diâmetro $>0,2 \mathrm{~mm}$ ) são herdados do material de origem. A dolomita em solos é quase que exclusivamente proveniente do intemperismo físico da rocha primária (Levy, 1981; Mermut \& Arnauld, 1981). A precipitação de carbonatos de cál cio e magnésio não é simplesmente o reverso da dissolução da cal cita e dolomita. Existe uma precipitação preferencial de $\mathrm{CaCO}_{3}$, a qual tem sido descrita por várias equações empíricas (Doner \& Lynn, 1989). A razão constante entre calcita e dolomita, determinável pela razão de intensidade dos respectivos picos nos difratogramas (Figura 1), étambém um indicativo de que o cal cário col etado nos filtros é litogênico.

A calagem estimula a atividade microbiana no solo, através da el evação do pH , o que implica maior produção de $\mathrm{CO}_{2}$. Com o aumento da pressão parcial de $\mathrm{CO}_{2}\left(\mathrm{pCO}_{2}\right)$, há um aumento da solubilidade do cal cário (Salomons \& Mook, 1976). Entretanto, o carbonato pode precipitar novamente quando o produto de solubilidade é excedido, situação provocada pelo decréscimo da $\mathrm{pCO}_{2}$ e aumento da concentração do sol uto. Desta maneira, o decréscimo da $\mathrm{pCO}_{2}$ com a profundidade do solo poderia favorecer a preci pitação do cal cário a partir do sol uto percolado. Assim, diante das condições inerentes do sistema plantio direto, a ocorrência desse mecanismo não pode ser descartada.

\section{Calagem superficial e composição da solução percolada}

A aplicação do calcário na superfície do solo, seguida da adição semanal de água em quantidade equivalente a uma chuva de $35 \mathrm{~mm}$, determinou aumento dos val ores de $\mathrm{pH}$, condutividade elétrica, cál cio, magnési o e bicarbonato na solução percolada, em relação à testemunha (Figura 4). Os maiores valores desses atributos foram observados após a primeira adição de água, indicando que os efeitos ocorreram rapidamente e estão relacionados com a quantidade de partículas transportadas (Quadro 1). Deve ter havido efeito tanto das partículas que desceram sem reagir e que depois se dissolveram na solução percolada, como das partículas que se dissolveram na superfície do solo com posterior descida dos produtos de sua dissolução. I sto caracteriza uma espécie de frente de alcalinização, sendo os produtos da dissolução do cal cário $\left(\mathrm{Ca}^{2+}\right.$, $\mathrm{Mg}^{2+}, \mathrm{HCO}_{3}{ }^{-}$) transportados juntamente coma água infiltrada e percolada.
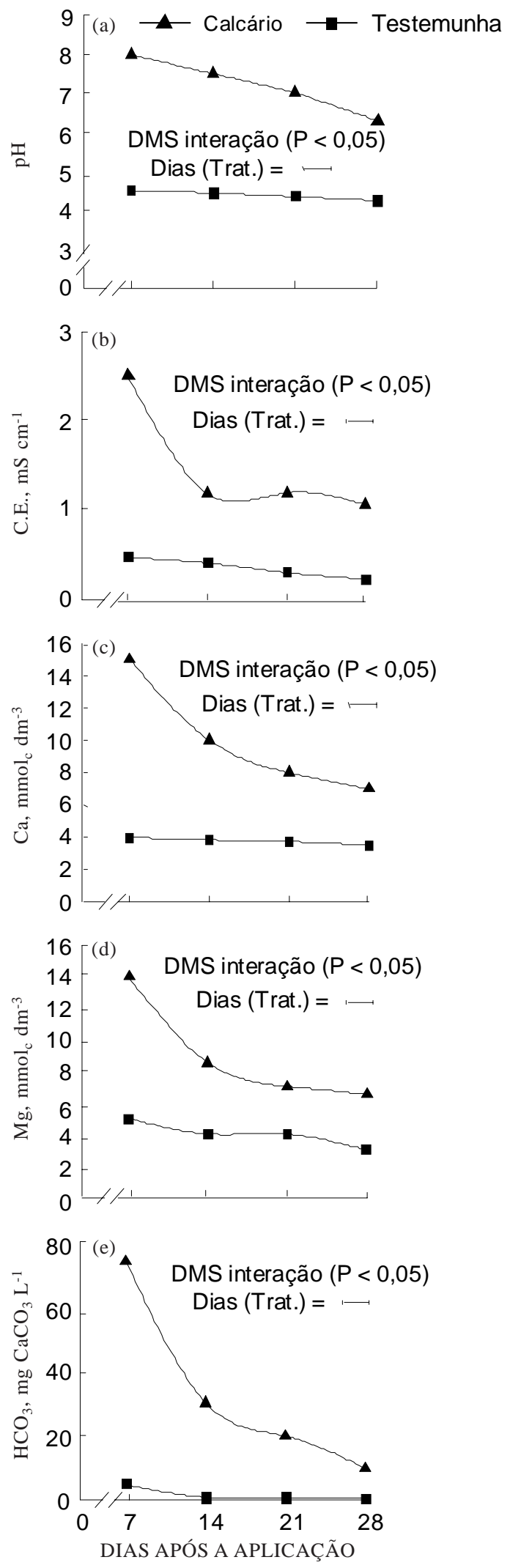

Figura 4. Valores de pH (a), condutividade elétrica (CE) (b), cálcio (c), magnésio (d) e bicarbonato (e) da solução percolada de acordo com as épocas de adição de água sobre o solo com e sem calcário superficial. 
Os valores dos íons $\mathrm{Ca}^{2+}, \mathrm{Mg}^{2+} \mathrm{eHCO}_{3}^{-}$na sol ução percolada poderiam dar suporte à hipótese de repreci pitação de carbonatos no sol o (Doner \& Pratt, 1969). A presença desses íons na solução percolada indica que a perturbação provocada pela calagem ultrapassou a capaci dade deamortização do sistema solo e provocou um novo estado em relação à testemunha. Porém, alterações no subsistema mineralógico não se manifestam rapidamente, dada a lentidão dessas reações (Azevedo et al.,1996).

\section{Calagem superficial e atributos químicos no perfil do solo}

A aplicação do calcário na superfície do solo aumentou o pH e o cálcio e o magnésio trocáveis e diminuiu o teor de alumínio trocável, em relação à testemunha (Figura $5 a, b, c, d, e)$, cujo efeito já havia se manifestado na água percolada (Figura 4). A capacidade de troca de cátions (CTC) efetiva $\left(\mathrm{Ca}^{2+}+\right.$ $\left.\mathrm{Mg}^{2+}+\mathrm{K}^{+}+\mathrm{Al}^{3+}\right)$ também foi maior no tratamento com cal cário e comportou-se semel hantemente aos val ores de cálcio(Figura 5f). A ação do calcário provocou a formação de gradientes nos atributos químicos a partir da superfície do solo, decorridos 28 dias da aplicação superficial do corretivo (Figura 5a,b,c,d,e). Os efeitos atingi ram todas as camadas, especialmente até $10 \mathrm{~cm}$ e, na última camada $(16-20 \mathrm{~cm})$, onde houve acúmulo do cal cário no filtro.

Como não houveacúmul o do corretivo nas demais camadas, deve ter ocorrido apenas o efeito dos (a) $\quad \mathrm{pH}, \mathrm{H}_{2} \mathrm{O}$

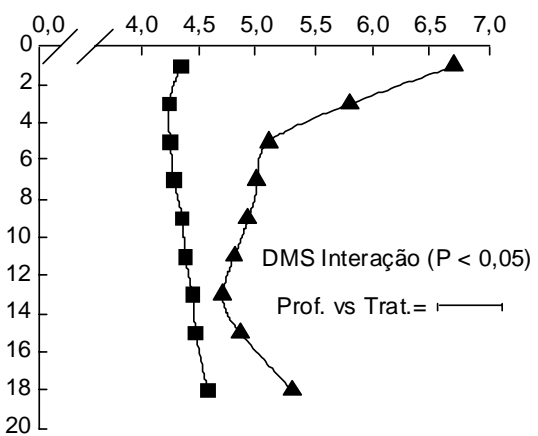

(c) Al TROCÁVEL, $\mathrm{cmol}_{\mathrm{c}} \mathrm{kg}^{-1}$

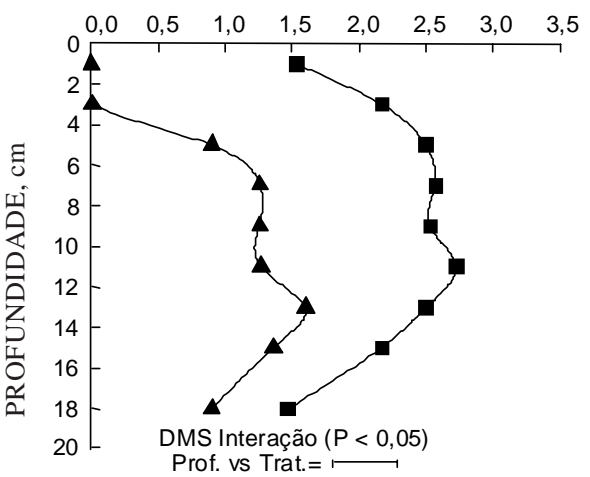

(e) Mg TROCÁVEL, $\mathrm{cmol}_{\mathrm{c}} \mathrm{kg}^{-1}$

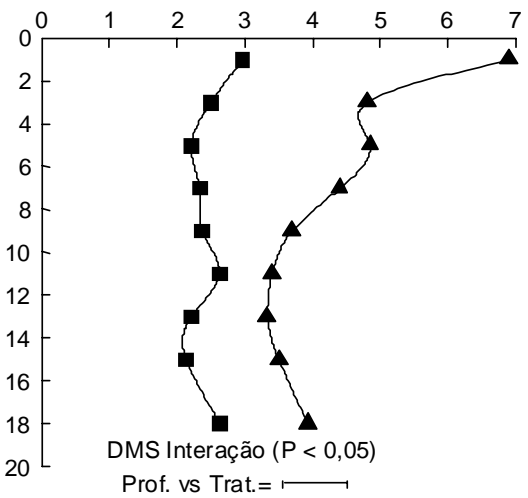

(b) $\mathrm{pH}, \mathrm{CaCl}_{2} \quad 0,01 \mathrm{~mol} \mathrm{~L}^{-1}$

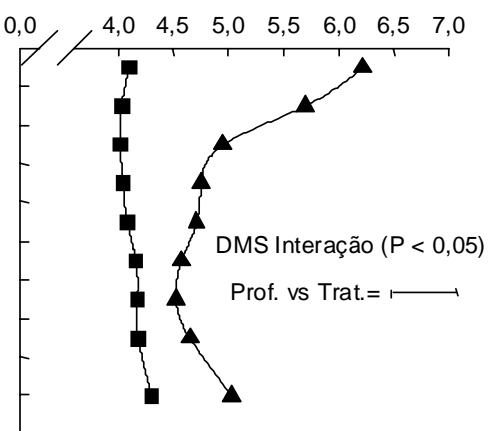

(d) Ca TROCÁVEL, $\mathrm{cmol}_{\mathrm{c}} \mathrm{kg}^{-1}$

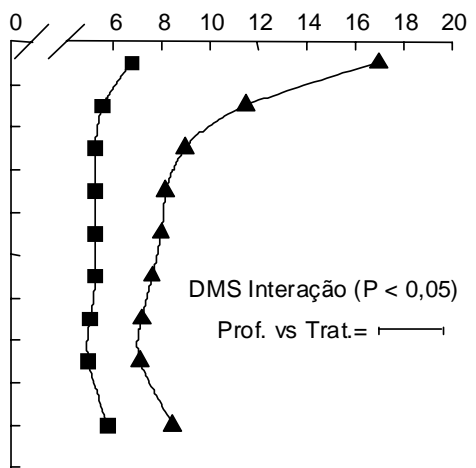

(f) CTC EFETIVA, $\mathrm{cmol}_{\mathrm{c}} \mathrm{kg}^{-1}$

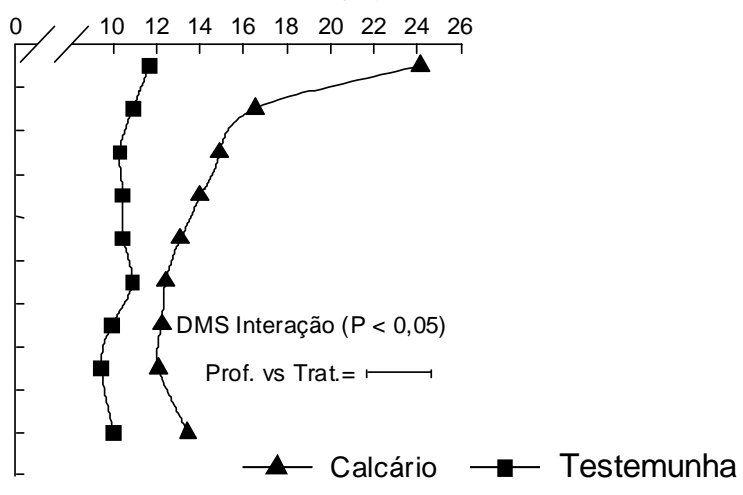

Figura 5. Valores de pH em água (a), $\mathrm{pH} \mathrm{CaCl}_{2} 0,01 \mathrm{~mol} \mathrm{~L}^{-1}(\mathrm{~b})$, alumínio trocável (c), cálcio trocável (d), magnési o trocável (e) e CTC efetiva $\left(\mathrm{Ca}^{2+}+\mathrm{Mg}^{2+}+\mathrm{K}^{+}+\mathrm{Al}^{3+}\right)(\mathrm{f})$ do solo quatro semanas após a aplicação ou não do calcário superficial. 
produtos de sua dissolução $\left(\mathrm{Ca}^{2+}, \mathrm{Mg}^{2+}\right.$ e $\left.\mathrm{HCO}_{3}{ }^{-}\right)$, indicando que, além do desl ocamento de partículas de cal cário não reagidas, houve também a formação de uma frente deal cal inização, a partir da superfície do solo, já evidenciada pelas análises da solução percolada (Figura 4). O uso do filtro simulou uma zona de impedimento, que pode ocorrer no solo em condições de campo, indicando que, caso não houvesse esse impedimento, as partículas de cal cário teriam atingido profundidades maiores.

As modificações nos atributos químicos do solo decorrentes da aplicação superficial de cal cário em campo (Sá, 1996; Pöttker \& Ben, 1998; Rheinheimer et al., 2000; Amaral \& Anghinoni, 2001) têm-se expressado em profundidades menores do que as do presente trabalho. Nesses trabalhos, com doses de calcário variando de 0,7 a $17 \mathrm{Mg} \mathrm{ha}^{-1}$ e tempo de aplicação de um a quatro anos, em solos com diferentes texturas, as camadas afetadas variaram de $2,5 \mathrm{~cm}$, para pH e alumínio trocável, a $12,5 \mathrm{~cm}$, para cálcio e magnésio trocáveis. Em trabalho similar, Petrere\& Anghinoni (2001) verificaram, em colunas indeformadas de solo, que, decorridas 25 semanas da aplicação do equival entea $6 \mathrm{Mg} \mathrm{ha}^{-1}$ de calcário dol omítico na superfície de um $L$ atossol o Vermelho distroférrico típico de campo nativo, os efeitos ocorreram até $7,5 \mathrm{~cm}$, para $\mathrm{pH}$ e alumínio trocável; até $10 \mathrm{~cm}$, para magnésio trocável, e até $5 \mathrm{~cm}$, para cál ci o trocável. Entretanto, somente dois dos trabal hos anteriormente citados (Rheinheimer et al., 2000; Petrere \& Anghinoni, 2001) admitem que os efeitos de calcário no perfil do solo tenham uma participação importante do transporte de partículas do cal cário.

Analisando as diferenças deste trabalho com as dos anteriormente referidos, destacam-se o menor tempo decorrido entre a aplicação do calcário e a avaliação dos seus efeitos no solo, a utilização de cal cário constituído de partículas mais finas $(0,105$ a 0,053 mm), a aplicação na superfície do sol o sem a presença de resíduos vegetais e o cultivo de aveia preta antes da aplicação do cal cário. A possibilidade de a decomposição das raízes ter influenciado a ação da calagem superficial existe, porém é pequena, principalmente porque, antes da aplicação do calcário, as colunas foram lixiviadas para eliminar os possíveis ácidos orgânicos remanescentes e o excesso de sais, porventura acumulados. Assim, pode-se afirmar que a ação do cal cário, que ocorreu de maneira rápida e em profundidade no perfil do solo, deveu-se majoritariamente ao deslocamento vertical de partículas do cal cário que não reagiram na superfície do solo e ao transporte dos produtos de sua dissolução através da solução percolada.

\section{CONCLUSÕES}

1. Houvetransporterápi do de partículas finas do cal cário da superfície até à profundidade de $20 \mathrm{~cm}$ pela água que percola no solo, sendo o transporte preferencial de partículas com diâmetro de $15 \mu \mathrm{m}$ ou menores.

2. O cal cário acumulado sobre os filtrsos col ocados na base das colunas de solo foi caracterizado como litogênico, pela razão constante entre as intensidades dos picos de cal cita e dolomita.

3. A identificação do cal cário no interior do solo podeindicar que os efeitos na neutralização da acidez e no aumento de cál cio e magnésio na subsuperfície do solo foram, em grande parte, devidos ao movimento vertical de partículas do cal cário.

4. Os efeitos na correção da acidez no perfil do sol oforam rápidos eintensos, o que permite enfatizar a importância do transporte de calcário através da água da chuva no sistema plantio direto com reaplicações do corretivo na superfície do solo ao longo do tempo.

\section{LITE RATURA CITADA}

AMARAL, A.S. \& ANGHINONI, I. Alteração de parâmetros químicos do solo pela reaplicação superficial de cal cário no sistema plantio direto. Pesq. Agropec. Bras., 36:695-702, 2001.

ARNAULD, R.J S.T. Nature and distribution of secondary soil carbonates within landscapes in relation to soluble $\mathrm{Mg}^{2+}$ $\mathrm{Ca}^{2+}$ ratios. Can. J. Soil Sci., 59:87-98, 1979.

AZEVEDO, A.C.; KÄMPF, N. \& BOHNEN, H. Alterações na dinâmica evolutiva de latossolo bruno pela calagem. R. Bras. Ci. Solo, 20:191-198, 1996.

BERTOL, I.; SCHICK, J . \& MASSARIOL, J .M. Propriedades físicas de um Cambissol o Húmicoálico afetadas pel o manejo do solo. R. Ci. Rural, 30:91-95, 2000.

COMISSÃO DE FERTILIDADE DO SOLO - CFRS/SC. Recomendações de adubação e de calagem para os estados do Rio Grande do Sul e Santa Catarina. 3.ed. Passo Fundo, Sociedade Brasileira de Ciência do Solo - Núcleo Regional Sul; EMBRAPA/CNPT, 1994. 224p.

DONER, H.E. \& LYNN, W.C. Carbonate, halide, sulfate and sulfide minerals. In: DIXON, J.B. \& WEED, S.B., eds. Minerals in soil environments. 2.ed. Wisconsin, Soil Society of America, 1989. p.279-324.

DONER, H.E. \& PRATT, P.F. Solubility of calcium carbonate precipitated in aqueous solutions of magnesium and sulfate salts. Soil Sci. Soc. Am. J ., 33:690-693, 1969.

EMPRESA BRASILEIRA DE PESQUISA AGROPECUÁRIA EMBRAPA. Manual de métodos de análises de solo. 2.ed. Rio de J aneiro, Serviço Nacional de Levantamento e Classificação do Solo, 1997. 247p.

GASSEN, D.N. \& KOCHHANN, R.A. Benefícios da fauna do solo de plantio direto. In: NUERNBERG, N.J ., ed. Conceitos e fundamentos do sistema plantio direto. Lages, Sociedade Brasileira de Ciência do Solo/Núcleo Regional Sul, 1998. p.151-160. 
LEVY, R. I ons activity product of calcium carbonate precipitated from soil solutions of different degrees of supersaturation. Soil Sci. Soc. Am. J ., 45:1070-1073, 1981.

MERMUT, A.R. \& ARNAULD, R.J.S.T. A study of microcrystalline pedogenic carbonates using submicroscopic techniques. Can. J . Soil Sci., 61:261-272, 1981.

MOLOPE, M.B.; GRIEVE, I.C. \& PAGE, E.R. Contributions by fungi and bacteria to aggregate stability of cultivated soils. J. Soil Sci., 38:71-77, 1987.

PETRERE, C. \& ANGHINONI, I. Alteração de atributos químicos no perfil do solo pela calagem superficial em campo nativo. R. Bras. Ci. Solo, 25:885-895, 2001.

PÖTTKER, D. \& BEN, J.R. Calagem para uma rotação de culturas no sistema plantio direto. R. Bras. Ci. Solo, 22:675684, 1998.

RHEINHEIMER, D.S.; SANTOS, E.J .S.; KAMINSKI, J .; BORTOLUZZI, E.E. \& GATIBONI, L.C. Alterações de atributos do solo pela calagem superficial e incorporada a partir de pastagem natural. R. Bras. Ci. Solo, 24:795-805, 2000.

SÁ, J .C.M. Calagem em solos sob plantio direto na região dos Campos Gerais, Centro Sul do Paraná. In: SÁ, J.C.M., ed. Curso sobre manejo do solo no sistema plantio direto. Ponta Grossa, Fundação ABC, 1996. p.73-107.
SÁ, J .C.M. \& PETRERE, C. Desenvolvimento radicular da cultura do milho em solos sob plantio direto da região dos Campos Gerais e do Planalto Gaúcho. In: CURSO SOBRE MANEJ O DO SOLO NO SISTEMA PLANTIO DIRETO, 1995, Castro. Anais. Castro, Fundação ABC, 1995. p.172204.

SALOMONS, W. \& MOOK, W.G. I sotope geochemistry of carbonate dissolution and reprecipitation in soils. Soil Sci., 122:15-24, 1976.

SCHICK, J .; BERTOL, I.; BATISTELA, O. \& BALBINOT J r., A.A. Erosão hídrica em Cambissolo Húmico alumínico submetido a diferentes sistemas de preparo e cultivo do solo. I - Perdas de solo e água. R. Bras. Ci. Solo, 24:427436, 2000.

TEDESCO, M.J .; GIANELLO, C.; BISSANI, C. \& BOHNEN, H. Análise de solo, plantas e outros materiais. 2.ed. Porto Alegre, Universidade Federal do Rio Grande do Sul, 1995. 174p. (Boletim Técnico, 5)

TROLLARD, F.; BOURRIE, G. \& J EANROY, E. Trace metals in natural iron oxides from laterites: A study using selective kinetic extraction. Geoch. \& Cosmoch. Acta, 59:1285-1297, 1995.

WUEST, S.B. Soil biopore estimation: effects of tillage, nitrogen, and photographic resolution. Soil \& Till. Res., 62:111-116, 2001. 
A.S. AMARAL et al.

R. Bras. Ci. Solo, 28:359-367, 2004 